\title{
THE PSYCHOLOGY OF INVESTING: STOCK MARKET RECOMMENDATIONS AND THEIR IMPACT ON INVESTORS' DECISIONS (THE EXAMPLE OF THE POLISH STOCK MARKET)
}

\author{
Jakub KELLER - Radoslaw PASTUSIAK \\ (Received: 3 February 2014; revision received: 3 October 2014; \\ accepted: 6 October 2014)
}

\begin{abstract}
This study seeks to show the impact of stock recommendation reports on the efficiency of investments in the Polish stock market. The study is carried out in two stages: the first takes place at the micro-level and is based on a behavioural experiment, while the second focuses on the verification of our results obtained on a real market. The main assertion is that stock recommendations create heuristic effects among investors near the publication date of the recommendation. The ambiguity of the recommendations hinders investors' reliable and unequivocal evaluation in investment decisions. There are studies in this field for different stock markets and periods of time, but our research added significant new knowledge about the functioning of the Polish stock exchange. Our study fits into the mainstream analysis of outlining the behaviour of investors in the capital market. The research findings underpin our pessimism about the impact of stock recommendations on investors' behaviour.
\end{abstract}

Keywords: capital market, behavioural finance, behavioural biases, heuristics, trading, investments, Warsaw Stock Exchange

JEL classification indices: G01, G11, G23

Radoslaw Pastusiak, Professor, corresponding author. Head of the Department of Corporate Finance, University of Lodz, Poland. E-mail: rpastusiak@uni.lodz.pl

Jakub Keller, MA, Assistant Professor at the Department of Corporate Finance, University of Lodz, Poland. E-mail: keller.jakub@wp.pl 


\section{INTRODUCTION}

Stock recommendations published by the brokerage houses exist in order to provide clients with a competitive advantage over other market participants. The impact of the recommendations on share prices has been in the centre of researchers' attention for a long time. The findings depend on the studied capital market and the type of research methods. This study seeks to analyse the influence of stock recommendations on the decisions of investors. Our analysis is based on data obtained from the Warsaw Stock Exchange (WSE) and recommendations received from brokerages and specialised websites. The present study examines the relation between stock recommendations and the price changes on financial markets, followed by a detailed look at the impact of recommendations on large and small companies as well as a thorough analysis of the increased effectiveness of positive recommendations.

Additionally we gathered data from a behavioural experiment, namely a trading game, which was conducted twice with a selected group of respondents. The importance of the behavioural experiment is underpinned by the fact that target prices and investment decisions should be determined not only by mathematical calculations. Despite some well-established procedures and diagrams used for the recommendations, we also have to pay attention to subjective factors and assumptions in the evaluation process. This means that we can verify the results based on the objective factors with probable, subjective erroneous factors resulting from heuristics. Several research studies indicate that many recommendation reports that neglect subjective factors are misleading, and make it more difficult for investors to succeed in the stock market.

The reports containing studies on companies made by financial institutions have specific effects among investors, such as the "Guru effect" - namely, investors will tend to base their decisions on the suggestions and not on their own analysis, assuming that these reports were elaborated by specialists. Despite the suggestions made by specialised institutions, we uphold that due to the large amount of information regarding the companies and the stock market, as well as the high volatility of share prices on the WSE, investors disregard potentially relevant information, through the quick purchase or sale of shares. This can be explained by the heuristic effect, leading to prompt and hasty action, as described in Kahneman and Tversky's decision and risk theory. These two approaches (the involuntary acceptance of the information "from the Guru" and the chaotic action without the considering of information) distort the objective analysis and introduce subjectivity in decision-making, often resulting in financial losses. 


\section{PREVIOUS STUDIES}

Traditional finance is based, inter alia, on two fundamental assumptions (Nofsinger 2011): people make rational decisions and they are impartial in predicting the future. Over time, it turned out that these theories often fail. The paradoxes and anomalies in the behaviour of market participants has led to a behavioural finance approach. However, the pioneers of this approach were at first considered heretical. Now the situation is changing. Today, the pioneers of behaviorism in finance are no longer called heretics, but visionaries. Although there are controversies regarding how, when and why mentality affects economic decisions, it is commonly believed that the granting of the 2002 Nobel Prize in economics to psychologist Kahneman and supporter of experimental economics Smith confirmed the validity of the direction of behavioural economics ${ }^{1}$. Vissing-Jorgensen (2003) directly proved the validity of behavioural theories and the importance of this approach for the study of finance. She also noted that behavioural theories explain the frequent and wide anomalies in economics.

Prospect theory is mostly mentioned as the main theory of behavioural finance, explaining a part of "irrational" consumer behaviour. This theory was developed by Kahneman and Tversky (1979) as an alternative to the theory of expected utility. The prospect theory explains human behaviour in terms of risk. It shows how people shape their attitude towards values, how they evaluate and treat chances of winning. This theory is often used in marketing (e.g. prices in supermarkets are always discounted to show how much the customer gains at the current price and suggests specified returns), but it is also applied in order to explain the behaviour of investors (e.g. why an investor does not cut loss position - further losses already causing less impact on its usefulness).

We should also look at other psychological effects that influence investment decisions. One of them is the sunk costs effect, which appears at a time when expenditures have been incurred to achieve a certain goal. Arkes - Blumer (1985) demonstrated that in order to achieve profits, an investor is more likely to retain the already started investment rather than abandon it and start a new one. This effect is also based on the prospect theory, which we will repeatedly refer to in our study.

The snake-bite effect is a reduction of the investors' investment position as a result of loss (Nofsinger 2011). An investor who has suffered a loss will open more positions involving smaller amounts, or will eventually stop investing. The

Advanced information on the Prize in Economic Sciences 2002, 17 December 2002. http:// www.nobelprize.org/nobel_prizes/economic-sciences/laureates/2002/advanced-economicsciences2002.pdf 
snake-bite effect can also trigger an aversion to the instrument (risk aversion). Another well-known heuristic effect is the endowment effect. Research conducted by Samuelson - Zuckhaustera (1988) showed that investors tend to stick to their assets even if it is incompatible with their level of risk acceptance. The predisposition effect manifests itself in the premature sale of profitable assets and maintaining the loss position for too long. Shefrin - Statman (1985) proved that this effect is caused by pride and fear of a sense of shame. This effect weakens with the investor's growing experience, however, it does not mean that experienced investors can completely avoid the problem.

Investigations on the impact of recommendations on price changes have been carried out since 1933, when the first study was published by Cowles (1933). He concluded that most of the recommendations do not provide valuable information. In subsequent years, recommendations were scrutinized multi-dimensionally. The result was a series of studies in which the authors often came to different conclusions.

Liu (1990) demonstrated the impact of recommendations on prices on the publication day. In the last two decades, valuable research on recommendations was conducted by Stickel (1995). He found different results, depending on the institution publishing the reports - that is, investors do not consider all the recommendations, but only the specific ones. However, Walker - Hatfield (1996) showed that investors do not have the additional benefits of using recommendations.

Clark (1983) studied the recommendations issued between 1995 and 2001, and tried to prove how excessive optimism influenced business decisions. His results do not support the hypothesis on excessive optimism. In contrast, Barber et al. (1998) demonstrated that a positive recommendation has a higher rate of return, while a negative one has a lower rate of return. The results have been related to a market benchmark, indicating a significantly higher rate of return in the proposed strategy in which recommendations were used. Jaffe - Mahoney (1999) examined the costs of obtaining recommendations and found that if these costs are taken into account, investors do not achieve additional gains from recommendations. Juergens (1999) showed that applying the recommendations leads to above-average returns. He analysed 3,679 recommendations and reports of companies in the IT sector. Ho - Harris (2000) demonstrated that besides recommendations, investors also use their own basic economic information and indices. Their optimism about the effectiveness of recommendations is limited. Aitken (2000) analysed the Australian Stock Exchange in the period between 1992 and 1998, and showed that the recommendations of real estate agents cause changes to the prices of entities related to the industry on the publication day. Barber et al. (2001) analysed the NYSE and demonstrated that investors' short-term strategies based on the recommendations provide profits to investors, but their profitability 
can be seriously reduced by the cost of frequent transactions. Azzi et al. (2005) analysed the distortion of the European analysts' recommendations. Investors interpret recommendations randomly. If the recommendation is negative for market growth, it has less impact on share prices, while if the trend is positive, it does not reflect the full scale of growth. Fang - Yasuda (2005) demonstrated the usefulness of recommendations and their effect on more profitable investments based on the recommendations. Chang - Chan (2008) noted that the recommendation effect depends on the brokerage house that prepared it, the company which it relates to, and its size and age. Loh - Stulz (2009 concluded that about $25 \%$ of the recommendations had no effect on market transactions, and only about $10 \%$ was very significant. The psychological factors affecting the investors' behaviour without stock recommendations should also be under scrutiny. In this context, an interesting paper was published by Swol - Sniezek (2005) based on two experiments about trust and confidence, from which they concluded that the high confidence of advisors result in a higher probability of the acceptance of their advice.

Another study published by Dunning et al. (1990) examined the issue of confidence and its role in the decision-making processes. They conducted a game experiment in which participants took the role of analysts and made predictions based on some selected information. The results indicated that participants were generally likely to be overconfident in every aspect tested in the experiment. Harvey - Fischer (1997) analysed the rationale behind taking advice. Their conclusions showed that people want advice for the most important decisions and they look for somebody to share the risk with. Because of the risk associated with stock investing, we think that this result is an important justification for brokerage recommendations. Peterson - Pitz (1988) tested the decision-making process in the context of the information gathered and confidence of the participant. Their research showed that uncertainty increases when the problem's difficulty level is higher. It shows that investors become confused while gaining increasingly more information, which is typical in modern markets. Yaniv - Kleinberger (2000) highlighted the conflict between advice and one's own opinion. They found that people confront the advice received with their own opinion and they often discount it for their own personal reasons. Another significant conclusion is that advisors can lose their reputation very quickly because of the long process of proving that their advice was good. Sniezek - Buckley (1995) carried out a game experiment in which participants had to make a decision between two alternatives with the help of an advisor. The authors focused on the time of the advice. They were interested in the impact of the recommendation before preparing one's own judgment or after it. The results revealed that the recommendation affected the final choice reliably and confidently. It means that the time of receiving the additional information is crucial. Premium stock investors who receive recom- 
mendations earlier than others make their decisions in a different way than small investors. Sniezek - Van Swol (2001) published a study examining the role of trust in decision-making. They established that the advisor's reputation is a very important factor of the counselling and decision-making.

\section{OUR RESEARCH METHODOLOGY}

In order to analyse our hypotheses, that recommendations are affecting the decision making process at the micro-level, we performed a behavioural experiment as a simulation game. The experiment was based on two trading games in simulated market conditions. Respondents were asked to react in real time to changing stock prices and to try to maximise the return on assets held by optimising its structure in their investment portfolios. Two companies were selected from the Warsaw Stock Exchange: KGHM Polska miedź S.A. and Boryszew S.A. ${ }^{2}$. The respondents did not know the names of the companies. The respondents were offered the option that if they bought bonds, this would give them a steady income.

The respondents were students of the Department of Finance and Accounting from the University of Lodz. The experiment was divided into two parts. The first part involved 139 and the second 145 participants. The respondents were further differentiated in terms of sex, knowledge of the capital market (enough - 1, above average -2 , good -3 , very good -4 , outstanding -5 ) and genuine market investment experience (or lack thereof). Respondents had to fill out the questionnaire on their own. To reduce the subjectivity in assessing the level of market knowledge, sample questions about the capital market were assigned to each survey.

The 10 years between 2002 and 2012 were compressed into 20 cycles showing security price changes for every six months. During the experiment, the real prices of a security were shown to the respondents who had to modify their investment portfolio accordingly. In order to reflect the high price volatility (rapid changes), new quotations for securities were displayed at one minute intervals. The participants had to change their portfolio in order to maximize the return of investments after a specified period.

Respondents participated in the process of real investment in shares over a 10 -year-period. The initial information was only the standard deviations calcu-

2 KGHM is one of the largest producers of copper and silver in the world. The mining and metallurgy company is located in Lublin. Boryszew S. A. produces components for the automotive trade, chemical materials, metal oxides, and other metal elements, and is located in Sochaczew. 
Table 1. Distribution and nature of recommendation for 2nd meeting of the experiment

\begin{tabular}{|c|c|c|c|c|c|c|c|c|c|c|c|c|c|c|c|c|c|c|c|c|}
\hline $\begin{array}{l}\text { period } \\
\text { / stock }\end{array}$ & 1 & 2 & 3 & 4 & 5 & 6 & 7 & 8 & 9 & 10 & 11 & 12 & 13 & 14 & 15 & 16 & 17 & 18 & 19 & 20 \\
\hline A & & & 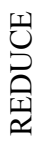 & & & & 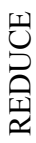 & & & & 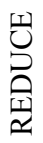 & & & & 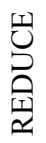 & & & & & \\
\hline B & & خ & & & & 它 & & & & $\zeta_{0}$ & & & & خ & & & & & & \\
\hline
\end{tabular}

Source: Own work.

lated from the concrete daily returns for each security during the experiment. The polled had information about price changes in every half-year period. As we mentioned above, participants did not know the names of the companies, so they could only respond to the changes to the prices of individual stocks.

The experiment was conducted twice. The first time, participants were not given any additional information beyond the historical standard deviation of prices and subsequent quotations of shares. At the second meeting, we introduced additional information: the recommendation reports for the listed companies. Some of them were "hit" and some "wrong", reflecting a normal market situation. Again, respondents had to maximize the rate of return of their portfolio. We assume that if recommendations have a real impact on investors' decisions, they will change the structure of their portfolios accordingly; decrease the "sell" and increase the "buy" share. To avoid inconclusive recommendations, we did not use "neutral" ones. Table 1 shows the type of the recommendations published in the experiment.

It should be added that the recommendations contained target prices anticipated by the analysts so the participants could estimate the potential growth of the price. It is also important that each recommendation was shown prior to the disclosure of the quotation for the current period, so that participants could make recommendation-based decisions even in the period of publication. However, we assumed that in the process of decision-making some inertia may occur, which may result in the delay of decision caused by short intervals of time between successive quotations and fear of using the information without verifying it with the next quotation given by subsequent action. For these reasons we have devoted particular attention not only to the time of publication, but also the later process. 
The impact of different types of recommendations for investment decisions seems to be an interesting field of our study. For this reason we also analysed the influence of positive and negative recommendations, assuming that their efficiency on investors may be asymmetric. In the subsequent analyses the number of signals coming from recommendations converging with the actual changes to shares in the portfolio has been counted and subgroups based on the number of proper reactions in different periods of trading have been created. Then the results between the workshops have been compared.

The second part of the research was based on a similar understanding of the impact of recommendations on changes to stock prices, but the analysis was transferred to the field of the real market. In order to verify the hypotheses stated previously, recommendations for companies included in the WSI20 were used. We used the recommendations from the period $01.2009-07.2012$ obtained from the Polish finance portal bankier.p ${ }^{3}$ and the major Polish brokerage houses websites. The total number of reports used in the study is 786 , which represents the vast majority of recommendations that were published during this period for the analysed companies. Of course we cannot be sure that the recommendation list covers $100 \%$ of the reports, but bankier.pl portal claims to be collecting all the recommendations for the companies listed on WSE from the Polish brokerage houses and the well-known foreign institutions. That leads to the conclusion that the gathered research sample is representative for the market. Using the assumption of the rapid discounting of information in the prices and the occurrence of affect heuristic, we specifically focused on the analysis of quotations in the vicinity of the publication of recommendations. Verification of hypotheses stated has been made: 1 and 5 days from the publication of the report. It is also assumed that the affect heuristic may not be biasing the market strongly, therefore, the period of verification of usability of recommendations may be longer. To take this possibility into account we also performed analysis in the horizon of one month from the date of publication. As in the case of experiments with a group of investors, each type of recommendation accounts for separate points of interests for us. However, the difference in comparison with the first part of the study was that in the context of the whole stock market, we analysed 5 subgroups of recommendations: buy, accumulate, neutral, reduce and sell. We have to note that we are aware of the controversial nature of using econometric methods to describe and uncover the occurrence of the behavioural effect among the investors, due to the fact that the psychological effects can be very individual. But as the particular cognitive biases are occurring in larger numbers causing anomalies, the language of statistics starts to be justified in our opinion.

3 http://www.bankier.pl/gielda/rekomendacje 
It also should be noticed that the movement of stock prices can be determined by many different factors and the assumption that they are free of distortions is obviously misleading. Existing market conditions that affect recommendations influence the prices that are so varied that capturing similar conditions is practically impossible, therefore we decided to apply a holistic approach. Our point of view on the behavioural aspects of investing can be an important step to harmonize the known effects from the statistical standpoint.

\section{RESULTS AND CONCLUSIONS}

We carried out a game-experiment in which the goal was to maximize the investment performance in shares in the subsequent 20 periods of time. The volatility of securities used in the study was presented in Charts 1 and 2.

In order to ensure the comparability of the results of the two workshops (Workshop 1 and 2), in both experiments the same shares were used. However, to prevent participants from identifying them as the same, which could distort their decisions, we introduced an additional, third security, different for each workshop, which was subsequently omitted in the course of comparisons. Furthermore, the order of securities has been changed, and prices during the second experiment were multiplied by a constant unusual factor (selected randomly) that caused significant distinction between nominal prices. During the second meeting, the

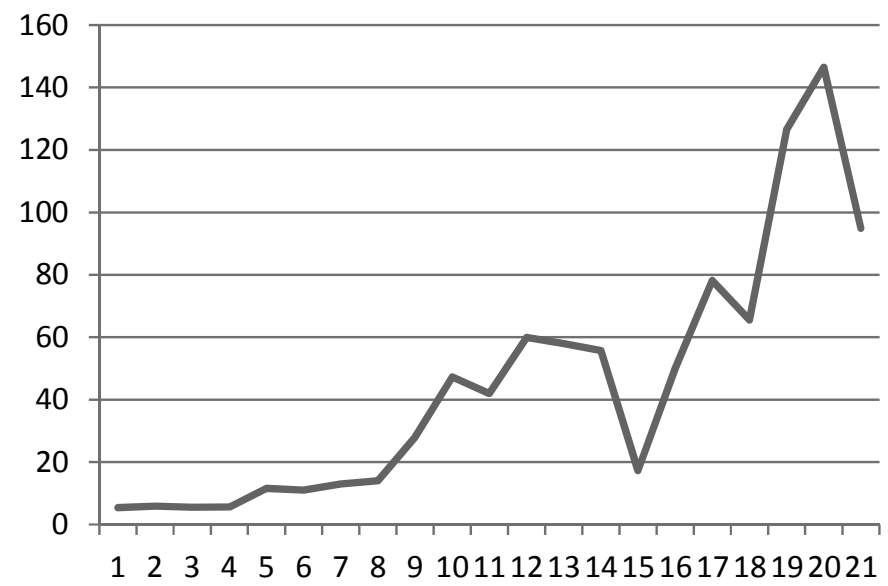

Chart 1. Stock A price volatility during the whole experiment (in PLN)

Source: Own work. 


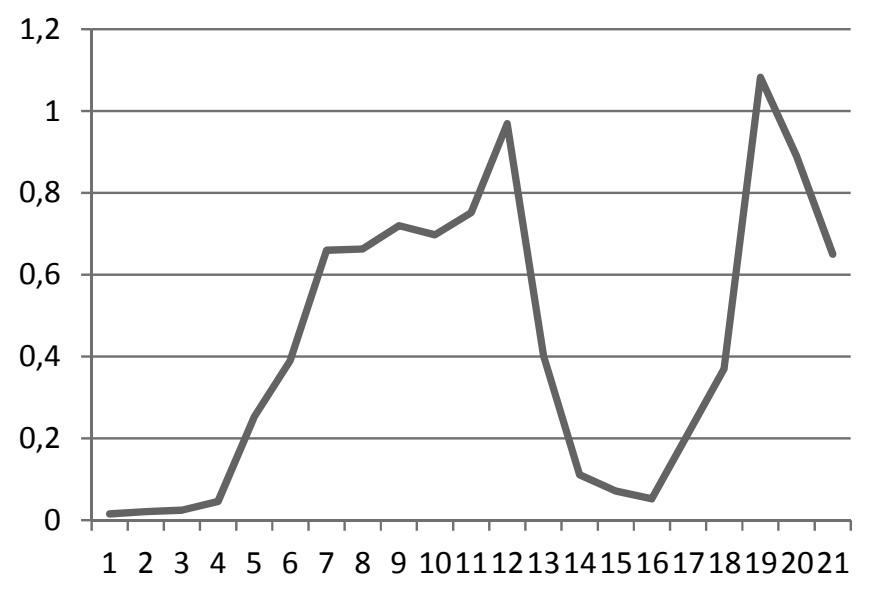

Chart 2. Stock B price volatility during the whole experiment (in PLN)

Source: Own work.

information for the investors has been enriched also with stock market recommendations, according to Table 1 .

In accordance with the research methodology, we focused on the reactions of investors immediately at the time of the publication of recommendation and also right after $i^{4}{ }^{4}$ in Workshop 2. For comparative purposes, the results obtained were collated with the corresponding periods of Workshop 1. We wanted to know whether there was a difference between the number of respondents who would react as suggested by the recommendations though it was not given to them. As four recommendations appeared for every share, we could observe a situation in which the investor had never reacted according to the report, or the opposite, a participant each time took a decision according to the recommendations, during the period of publication or the following one. The following method was used for indication:

- A0 - number of people who invested contrary to the recommendation every time,

- A1 - number of investors that reacted in accordance with the recommendation 1 time,

- A2 - number of investors that responded in accordance with the recommendation 2 times,

$4 \quad$ The results are available from the authors upon request. 
- A3 - number of investors that reacted in compliance with the recommendation 3 times,

- A4 - a number of situations in which investor acted as stated in the report every time.

The key for the analysis is the extreme cases of reaction to published reports, for which we consider the situation A0, A3 and A4, because they clearly reflect the impact of recommendation on investors. In the case of share A3, 4 the number of participants who decided to follow the report in their decisions 3 or 4 times was lower than in the first workshop. This applies to both the publication and the period defined as "inertia", so a delayed reaction. It should be emphasised that the recommendations for share rather reflect the general trends in price movement so observers had an empirical proof that they are made correctly. We also observe a significant increase in the number of people who have decided to act contrary to the proposed analysis. A reduced number of investors tending toward recommendations and an increase of approx. $16 \%$ in the number of people who completely ignored the reports lead to the conclusion that the recommendations did not influence the decision-making process of the investors. We suspect that investors' reaction might be determined by their suspicions that the proposed reports were aimed at misleading them, resulting in inverse reactions than expected. However, it should be noted that during the experiment it was clearly underlined that the volatility of shares and the recommendations have not been prepared specifically for the workshop, but these were real quotations from the WSE as well as the randomly chosen analytical recommendations that were published at that time.

In the case of share B, we observed analogous trends to share A. Here we noticed a clear increase in the number of people who behaved completely contrary to the recommendations. And in the case of those who responded accordingly to the direction indicated by the reports 3 or 4 times, we observed nearly the same number of people who have trusted the analysts creating the given recommendation. In the case of share B, investors could observe a very dynamic growth of rates of return in the first part of the study, which was further supported with the "buy" recommendations. This situation changed, however, in the vicinity of period 12 , where there was a sharp fall in prices, which could surely deter investors from that security despite the subsequent "buy" recommendation.

It should also be noted that in this situation, both for shares A and B, investors had to suffer a huge cognitive dissonance because their existing investments turned out to be noncompliant with the analytical reports - for systematically increasing the price of shares A against the "reduce" recommendations - or they suddenly turned out to be huge mistakes - in the case of share B. This situation induced the peculiar remorse and sorrow, which deterred a vast majority of in- 
vestors from constant use of the recommendations (snake-bite effect). We also presume that the small group of investors - three participants - confirm the existence of the effect of sunk costs in the case of share B. Despite the loss of almost all the capital invested in this stock, investors are still allocating their money in the specified share despite all the negative information that emerged during the experiment. That reaction was probably also supported by receiving a kind of confirmation of that decision in the latter published "buy" recommendations. However, due to the number of respondents in this group, and their anonymity, which makes it impossible to reach directly these three people, we could not utterly verify whether this effect actually was the main cause of such behaviour.

We treat the accomplished workshop like a guideline for further observation and extending the subject matter of that research. However, the experiment is a valuable research study material for the assessment of individual investors' behaviour. The general conclusion of the experiment is the statement that the recommendations are overlooked by investors when making their investment decisions. We do not deny that there is a group of investors, which uses this type of reports for decision-making, but recommendations as a tool to make investments decisions are generally ineffective.

In order to confirm this thesis, an analysis of volatility of the main index of the WSE in the context of published analytical reports was conducted. We examined the volatility of stock prices at the time of publication of 788 recommendations issued between 2009 and 2013. The aim of the analysis was to confirm the occurrence of above average rates of return for the shares after the release of the report. As in the case of the earlier experiment, we assumed that investors might react to the recommendations at different speed, which could have been caused by different access to information, delays in the publication of the recommendations in public sources and market liquidity itself.

It should be noted that the analytical reports are methodologically very ambiguous. We even cannot observe the clear limits of potential changes in asset prices assigned to a specific type of recommendation (buy, sell, etc.).

We have four values characteristic for each subgroup of recommendations, so we observe that for all the "buy" recommendations, which were included in the research sample, the lowest recorded price of potential growth resulting from the recommendation was only $1.22 \%$, while the most optimistic "buy" recommendation assumed the opportunity to increase prices by up to $133.39 \%$. An average of "buy" recommendation hovered around $23 \%$ and the median of about $20.4 \%$. Analysis of all subgroups of recommendations indicates that the limits are vague and overlapping. ${ }^{5}$

5 The results are available upon request. 
Table 2. Standardized threshold limits of the potential change in price for each type of recommendation

\begin{tabular}{lc}
\hline Established threshold limits for recommendation, $\%$ \\
\hline Sell & $<-15.00$ \\
\hline Reduce & -9.00 \\
\hline Neutral & 13.00 \\
\hline Accumulate & 23.00 \\
\hline Buy & $23.00<$ \\
\hline
\end{tabular}

Source: Own work.

You will notice that the heterogeneity of the reports made by various institutions leads to a situation in which, at the assumed potential price change, analysts can issue quite varied final assessments from "buy" to "sell". This situation greatly complicates the unambiguous perception of the published reports, which is also translated into lower, subjective assessment of their reliability in the eyes of investors, who, in this case, will be less likely to use this type of information. We also point to the fact that there are a lot of published recommendations concerning the analysed companies, which, due to their size and liquidity, are in the centre of interest of the media and analysts. It hinders clear assessment of a longterm company, especially when reports appear frequently and do not coincide with each other. Due to a large amount of information and high frequency of the publication of recommendations, the reactions of investors can be observed only in a short period of time from the publication, even though the reports themselves refer to the time horizon of a year or more.

We used the standard and modified types of recommendation reports. We understand the investment signal coming from the recommendations is the potential change in prices. ${ }^{6}$ As in the first part of the experiment, we are primarily interested in analysing recommendation types that generate the strongest signals for price movement that is "buy" and "sell".

Table 2 indicates the threshold limits for each type of recommendation, adopted in order to eliminate overlapping intervals of potential growth in the price, which hinders clear analysis. The table shows that the type of "sell" recommendation defines all the reports indicating the growth potential of less than $-15 \%$. In the range of $-15 \%$ to $-9 \%$ there are "reduce" recommendations and respectively "buy" recommendations with the growth of over $23 \%$.

6 Unified thresholds defining the limits for every type of recommendation are available upon request. 
Table 3. Co-directivity of recommendation or price change and the number of changes greater than the standard deviations

\begin{tabular}{l|c|c|c|c}
\hline $\begin{array}{l}\text { Horizon, } \\
\text { days }\end{array}$ & $\begin{array}{c}\text { Directional } \\
\text { compatibility of } \\
\text { recommendation } \\
\text { with a genuine } \\
\text { price change }\end{array}$ & $\begin{array}{c}\text { Stock signal share } \\
\text { in the total number } \\
\text { of publications, \% }\end{array}$ & $\begin{array}{c}\text { Number of changes } \\
\text { greater than the } \\
\text { standard deviation }\end{array}$ & $\begin{array}{c}\text { Stock signal share } \\
\text { stronger than the } \\
\text { standard deviation } \\
\text { in compatible } \\
\text { signals, \% }\end{array}$ \\
\hline $\mathrm{t}+1$ & 410 & 52 & 110 & 27 \\
\hline $\mathrm{t}+5$ & 418 & 53 & 131 & 31 \\
\hline $\mathrm{t}+30$ & 428 & 54 & 112 & 26 \\
\hline
\end{tabular}

Source: Own work.

According to the accepted assumption, we analysed the price volatility after the release of the recommendations in three time horizons: 1 day, 5 days and 30 days. We analysed the volatility of prices in each of these horizons for every share separately in two sub-samples. The first one comprises all the quotations of the specified share, while the second contains just some part of it, occurring only right after the publication date of an analytical report. We compared the rates of return achieved in the whole time considered in the elaboration to those associated with the recommendation in order to check whether the appearance of the recommendation entails the rates of return greater than the standard one. In order to verify this thesis, the significance of differences between average rates of return for the total number of quotations and the average rate of return achieved in connection with the recommendation has been tested.

However, initially, we looked at the simple relation between the information coming from the recommendations and the stock price change, namely, the occurrence of co-directionality of the actual price changes to the potential changes assumed in the recommendation. Afterwards, we examined how many co-directional recommendations generate a rate of return higher than the standard deviation calculated for each share individually. The results are shown in Table 3.

Analysis of the price movement after the publication of the given recommendation shows that only about half of them seem to generate a change to the price according to its contents. Hence, it can be concluded that the recommendations do not vastly influence investors. Moreover, only about $27 \%$ of situations, in which the price change was compliant with the recommendation, shows the price higher than the standard deviation. If this number referred to the whole sample, not only to directionally compatible signals, we could say that only about $13 \%$ of recommendations have generated a financial surplus, which can be attributed to the publication of a report. This situation is very similar in each of the three time horizons analysed. 
Table 4. Significance of differences between average rates of return in total toward average rates of return after the publication of recommendations for period $t+1$

\begin{tabular}{l|c|c|c}
\hline \multicolumn{4}{|c}{$\mathrm{T}+1$} \\
\hline share & $\chi^{2}$ limit & U statistics & Statistical difference \\
\hline ACP & 44.99 & 21.94 & equal \\
\hline BHW & 61.66 & 71.44 & different \\
\hline BRE & 59.30 & 13.41 & equal \\
\hline BRS & 12.59 & 7.77 & equal \\
\hline GTC & 43.77 & 13.43 & equal \\
\hline KER & 32.67 & 26.17 & equal \\
\hline KGH & 84.82 & 68.37 & equal \\
\hline LTS & 66.34 & 31.49 & equal \\
\hline LWB & 55.76 & 56.62 & different \\
\hline PEO & 81.38 & 1618.83 & different \\
\hline PGE & 47.40 & 30.76 & equal \\
\hline PGN & 72.15 & 65.46 & equal \\
\hline PKN & 67.50 & 52.05 & equal \\
\hline PKO & 79.08 & 52.01 & equal \\
\hline PZU & 41.34 & 146.48 & different \\
\hline SNS & 35.17 & 15.50 & equal \\
\hline TPE & 31.41 & 1334.22 & different \\
\hline TPS & 73.31 & 20.60 & equal \\
\hline TVN & 69.83 & 27.21 & equal \\
\hline
\end{tabular}

Source: Own work.

The next step was to examine whether the average rates of return generated in the periods taking place immediately after the publication of a recommendation generate higher returns than averagely. The results were included in Tables 4, 5, 6.

As the analysis of a one-day time horizon shows, it is clear that only in the case of five companies the rates of return generated in the periods after the publication of the recommendations differ from the average ones. This represents approximately $26 \%$ of all analysed companies. The reason for this is the presence of relatively high variance of returns in terms of one session, which affects the statistic value.

When analysing the rates of return for five days from the publication of the recommendation, we can see that they do not differ statistically from the overall rates of return achieved for a given stock in 5 sessions. This may prove the initial assumption that the time of the reaction to the publication of the recommendations was right and if we want to analyse the impact of this type of information, we should focus on short research horizons. 
Table 5. Significance of differences between average rates of return in total toward average rates of return after the publication of recommendations for period $t+5$

\begin{tabular}{l|c|c|c}
\hline \multicolumn{4}{|c}{$\mathrm{T}+5$} \\
\hline share & $\chi^{2}$ limit & U statistics & Statistical difference \\
\hline ACP & 44.99 & 17.17 & equal \\
\hline BHW & 61.66 & 46.90 & equal \\
\hline BRE & 59.30 & 46.09 & equal \\
\hline BRS & 12.59 & 7.30 & equal \\
\hline GTC & 43.77 & 33.60 & equal \\
\hline KER & 32.67 & 23.05 & equal \\
\hline KGH & 84.82 & 68.93 & equal \\
\hline LTS & 66.34 & 52.94 & equal \\
\hline LWB & 55.76 & 43.12 & equal \\
\hline PEO & 81.38 & 65.73 & equal \\
\hline PGE & 47.40 & 29.91 & equal \\
\hline PGN & 72.15 & 56.67 & equal \\
\hline PKN & 67.50 & 50.93 & equal \\
\hline PKO & 79.08 & 66.23 & equal \\
\hline PZU & 41.34 & 26.08 & equal \\
\hline SNS & 35.17 & 15.36 & equal \\
\hline TPE & 31.41 & 20.30 & equal \\
\hline TPS & 73.31 & 52.00 & equal \\
\hline TVN & 69.83 & 54.83 & equal \\
\hline
\end{tabular}

Source: Own work.

Analysis of the monthly rates of return leads to similar conclusions to those from the five-day time horizon. On a monthly basis, the publication of recommendations on the stock market does not produce statistically significant difference between the average rates of return for each asset and the average, monthly rates of return in total.

\section{SUMMARY}

The different assumptions and methodology lead to different results pertaining to the stock recommendations' impact on stock prices. Also, it should be considered that researchers who used similar methodology came to different conclusions just because their studies were made at a different time and in varied markets. Thus, it can be concluded that the correlation between the stock market recommendations and the price change is not positive in general, but it might be, if we consider a specified market niche. 
Table 6. Significance of differences between average rates of return in total toward average rates of return after the publication of recommendations for period $t+30$

\begin{tabular}{l|c|c|c}
\hline \multicolumn{4}{|c}{$T+30$} \\
\hline share & $\chi^{2}$ limit & U statistics & Statistical difference \\
\hline ACP & 44.99 & 39.63 & equal \\
\hline BHW & 61.66 & 48.62 & equal \\
\hline BRE & 59.30 & 46.40 & equal \\
\hline BRS & 12.59 & 7.37 & equal \\
\hline GTC & 43.77 & 33.73 & equal \\
\hline KER & 32.67 & 25.97 & equal \\
\hline KGH & 84.82 & 68.49 & equal \\
\hline LTS & 66.34 & 54.03 & equal \\
\hline LWB & 55.76 & 38.76 & equal \\
\hline PEO & 81.38 & 66.29 & equal \\
\hline PGE & 47.40 & 22.73 & equal \\
\hline PGN & 72.15 & 53.91 & equal \\
\hline PKN & 67.50 & 52.50 & equal \\
\hline PKO & 79.08 & 68.60 & equal \\
\hline PZU & 41.34 & 27.41 & equal \\
\hline SNS & 35.17 & 16.35 & equal \\
\hline TPE & 31.41 & 23.42 & equal \\
\hline TPS & 73.31 & 50.45 & equal \\
\hline
\end{tabular}

Source: Own work.

Our study leads to the conclusion that the analytical reports are not significantly discounted by investors. Methodological ambiguity of stock recommendations hinders their reliability and unequivocal evaluation by their receivers, which respectively results in ignoring these reports while making investment decisions. Workshop experiments show that even if investors are supported by analytical studies or elaborations, they constitute a minority, for sure. This conclusion is also confirmed through the scrutiny of macro-level process. Estimations and tests performed on the Polish stock market reveal that the publications of analysts' stock recommendations do not seem to cause abnormal price movements. Certainly, there is a group of investors who are using some of the reports in their decisions, but their strength in the general market demand is relatively low and does not result in the effects that can be associated directly with the publication of the recommendation. We claim that the observed situation may be largely driven by methodological uncertainties, the asymmetry of information of investors and a big amount of information pertaining to the most powerful companies on the WSE.

One of the main differences between the presented research and the previous literature is how we approach the subject. Our study is divided into two parts: 
macro- and micro-levels, which help to understand the decision-making mechanisms of investors according to the stock recommendation reports. We focused on the behavioural aspects of investing and we tried to implement a statistical way of thinking to describe the subjective elements of the process. This point of view presents a special approach to the issue of stock recommendations. Our paper describes the meaning of recommendations for the Polish stock market, which has not been thoroughly examined yet, particularly in the context of behavioural finance.

We are aware that the proposed methodology is not unbiased, but in reference to a large amount of information discounted in the stock prices, it is a good foundation for the further research. It is difficult to unequivocally select the price volatility, which can be evoked only by the stock recommendation. For this reason, we would like to continue the analysis, isolating a number of different factors and research samples to evaluate the impact of stock recommendations. We are particularly interested in the subject and how the recommendation reports influence the decisions of investors to buy or sell shares by sector, liquidity and size of the companies. This type of study may disclose the specified group of shares that are more susceptible to the kind of information than the stock recommendation provides.

\section{REFERENCES}

Aitken, M. - Muthuswamy, J. - Wong, K. (2000): The Impact of Brokers' Recommendations: Australian Evidence. Pacific Basin Journal of Finance, 4(2): 297-314.

Arkes, H. - Blumer, C. (1985): The Psychology of Sunk Cost. Organizational Behavior and Human Decision Processes, 35(1): 124-140.

Barber, B. - Lehavy, R. - McNichols, M. - Tueman, B. (2001): Can Investors Profit from the Prophets? Security Analyst Recommendations and Stock Returns. Journal of Finance, 56(2): 531-563.

Barber, B. - Lehavy, R. - Trueman, B. - McNichols, M. (2001): Prophets and Losses: Reassessing the Returns to Analysts' Stock Recommendations. Research Paper, No. 1692, Stanford University, Graduate School of Business.

Barber, B. - Odean, T. (1998): The Courage of Misguided Convictions. Financial Analysts Journal, (12): 41-55

Chang, Y. - Chan, Ch. (2008): Financial Analysts' Stock Recommendation Revisions and Stock Price Changes. Applied Financial Economics, 18: 309-325.

Clark, T. - Weinstein, M. (1983) The Behavior of the Common Stock of Bankrupt Firms. The Journal of Finance, 38(2): 489-504.

Cowles, A. (1933): Can Stock Market Forecasters Forecast? Econometrica, 1: 309-324.

Dunning, D. - Griffin, D. W. - Milojkovic, J. D. - Ross, L. (1990): The Overconfidence Effect in Social Prediction. Journal of Personality and Social Psychology, 58(4): 568-581.

Fałkowski, A. - Tyszka, T. (2006): Psychologia zachowań konsumenckich (Psychology of Consumer Behaviour). Gdansk: GWP Uzdrowisko. 
Fang, L. H. - Ayako, Y. (2005): Are Stars' Opinions Worth More? The Relation between Analyst Reputation and Recommendation Values. Working Paper, Wharton School.

Harvey, N. - Fischer, I. (1997): Taking Advice: Accepting Help, Improving Judgment, and Sharing Responsibility. Organizational Behavior and Human Decision Processes, 7: 117-134.

Ho, M. J. - Harris, R. S. (2000): Brokerage Analysts' Rationale for Investment Recommendations: Market Responses to Different Types of Information. Journal of Financial Research, 23(4): 449-468.

Jaffe, J. F. - Mahoney, J. M. (1999): The Performance of Investment Newsletters. Journal of Financial Economics, 53(2): 289-307.

Juergens, J. (1999): How do Stock Markets Process Analysts' Recommendations? Working paper, Arizona State University, Finance Department.

Kahneman, D. - Tversky, A. (1979): Prospect Theory: An Analysis of Decision under Risk. Econometrica, 47(2): 263-291.

Kollock, R. (1994): The Emergence of Exchange Structures: An Experimental Study of Uncertainty, Commitment, and Trust. American Journal of Sociology, 100(2): 313-345.

Liu, P. - Smith, S. D. - Syed, A. A. (1990): Stock Price Reactions to the Wall Street Journal's Securities Recommendations. Journal of Financial and Quantitative Analysis, 25(3): 399-410.

Loh, R. - Stulz, R. (2010): When are Analyst Recommendation Changes Influential? Review of Financial Studies, 24(2): 593-627.

Nofsinger, J. R. (2011): Psychologia inwestowania (Psychology of Investing). Gliwice: Helion.

Peterson, D. K. - Pitz, G. F. (1988): Confidence, Uncertainty, and the Use of Information. Journal of Experimental Psychology: Learning, Memory, and Cognition, 14: 85-92.

Samuelson, W. - Zeckhauster, R. (1988): Status Quo Bias in Decision Making. Journal of Risk and Uncertainty, 1(1): 7-59.

Shefrin, H. - Statman, M. (1985): The Disposition to Sell Winners Too Early and Ride Losers Too Long: Theory and Evidence. Journal of Finance, 40(3): 777-790.

Sniezek, J. A. - Buckley, T. (1995): Cueing and Cognitive Conflict in Judge-Advisor Decision Making. Organizational Behavior and Human Decision Processes, 62(2): 159-174.

Sniezek, J. A. - Van Swol, L. M. (2001): Trust and Expertise in a Judge Advisor System. Organizational Behavior and Human Decision Processes, 84(2): 288-307.

Stickel, S. (1995): The Anatomy of the Performance of Buy and Sell Recommendations. Financial Analysts Journal, 51(5): 25-39.

Swol, L. - Sniezek, J. (2005): Factors Affecting the Acceptance of Expert Advice. British Journal of Social Psychology, 44(3): 443-461.

Tyszka, T. - Zaleśkiewicz, T. (2001): Racjonalność decyzji (The Rationality of the Decision). Warszawa: PWE.

Vissing-Jorgensen, A. (2003): Perspectives on Behavioral Finance: Does "Irrationality" Disappear with Wealth? Evidence from Expectations and Action. NBER Macroeconomics Annual, No. 18.

Walker, M. M. - Hatfield, G. B. (1996): Professional Stock Analysts' Recommendations: Implications for Individual Investors. Financial Services Review, 5(1): 13-29.

Yaniv, I. (1997): Weighting and Trimming: Heuristics for Aggregation of Judgments under Uncertainty. Organizational Behavior and Human Decision Processes, 69(3): 237-249.

Yaniv, I. - Kleinberger, E. (2000): Advice Taking in Decision Making: Egocentric Discounting and Reputation Formation. Organizational Behavior and Human Decision Processes, 83(2): 260-281. 